\title{
Histological characteristics of the largest and secondary tumors in radical prostatectomy specimens and implications for focal therapy
}

\author{
Young Hyo Choi, Ji Woong Yu, Byong Chang Jeong, Seong II Seo, Seong Soo Jeon, Hyun Moo Lee and
} Hwang Gyun Jeon ${ }^{*}$

\begin{abstract}
Background: Pathological features of prostate cancer in Korean men were analyzed to determine whether identification of tumor volume, Gleason score (GS), focality, and location using radical prostatectomy (RP) specimens can provide useful information for the application of focal therapy (hemiablation).

Methods: From January 2016 to December 2017, 913 patients who underwent RP at a single center were selected for analysis. Patients with prostate-specific antigen levels $>15 \mathrm{ng} / \mathrm{mL}$ or those who had received hormone therapy prior to surgery were excluded. Preoperative data and the number, volume, location, and GS of each tumor were recorded.

Results: Overall, 762 RP specimens were examined, and 1448 tumors were identified. The majority of the cases were multifocal (60.5\%) and bilateral (82\%) in nature. Among the 686 secondary tumors, 250 (36.4\%) had a GS $\geq 7$ and $122(17.8 \%)$ had a tumor volume $\geq 0.5 \mathrm{~mL}$. Among the 435 bilateral multifocal cases, secondary tumors on the lobes contralateral to the largest tumor were significant by volume $(\geq 0.5 \mathrm{~mL})$ in 91 (20.9\%) cases and by grade (GS $\geq 7)$ in 179 $(41.1 \%)$ cases. There were 102 (23.4\%) tumors with a small tumor volume $(<0.5 \mathrm{~mL})$ and Gleason pattern 4 on the lobe contralateral to the largest tumor.

Conclusions: Bilateral and multifocal tumors are a common feature and secondary tumors frequently exhibit clinically significant prostate cancer on RP specimens in Korea. In many cases, secondary tumors on the lobe contralateral to the largest tumor had a high GS and small tumor volume.
\end{abstract}

Keywords: Focal therapy, Hemiablation, Histological characteristics, Prostate cancer, Radical prostatectomy specimen

\section{Background}

Radical prostatectomy (RP) and whole-gland radiotherapy are currently the standard of care for definitive management of clinically localized prostate cancer. However, whole-gland therapy is often considered an unnecessary treatment or overtreatment for many patients [1]. In the last decade, focal therapy has been evaluated as an alternative treatment for selected men harboring localized prostate cancer. The aim of this tissue-preserving treatment is to maintain effective oncologic outcomes by selectively

\footnotetext{
* Correspondence: hwanggyun.jeon@samsung.com

Department of Urology, Samsung Medical Center, Sungkyunkwan University School of Medicine, 81 Irwon-ro, Gangnam-gu, Seoul 06351, South Korea
}

ablating known disease, while optimizing genito-urinary function $[2,3]$. Although partial resection or focal ablation in many solid cancers is acceptable in eligible patients, theoretical objections to focal therapy in prostate cancer include the multifocal nature of the malignancy $[4,5]$.

The rationale for focal therapy relies on evidencebased elements. First, the natural history of prostate cancer appears to be linked to the index tumor in the majority of men, and secondary low-grade tumors appear to exhibit indolent behavior in most cases [6-8]. Small, low-grade secondary tumors may therefore be clinically irrelevant if the index tumor can be ablated and controlled [9]. Second, there is growing evidence

(C) The Author(s). 2019 Open Access This article is distributed under the terms of the Creative Commons Attribution 4.0 International License (http://creativecommons.org/licenses/by/4.0/), which permits unrestricted use, distribution, and 
that multiparametric magnetic resonance imaging (mpMRI) detects both high-grade and larger tumors accurately $[10,11]$. Detection rates of clinically significant prostate cancer using mpMRI ranged from 44 to $87 \%$ in biopsy-naïve men and men with a prior negative biopsy. The negative predictive value of mpMRI for exclusion of significant cancer ranges from 63 to $98 \%$ [12].

Although mpMRI is promising for detection of larger tumors, it lacks sufficient sensitivity to detect smaller tumors. Approximately $20 \%$ of men had non-index tumors with a Gleason score (GS) $\geq 7$, but detection of these tumors was poor [13]. In addition, Korean patients with prostate cancer tend to have worse disease characteristics than Western men $[14,15]$. Korean men appear to have more high-grade tumors and more advanced cases than Western men, after adjusting for various confounding variables, such as age at surgery, preoperative levels of prostate-specific antigen (PSA), and clinical stage [15].

Thus, the aim of this study was to examine the largest tumors and smaller high-grade tumors that are easy to miss with mpMRI through final pathologic assessments of Korean patients who underwent RP. These data may be useful for informing patient selection for focal therapy. For example, data on the number of clinically significant small tumors remaining in untreated lobes following hemiablation would help determine appropriate courses of treatment.

\section{Methods}

\section{Patients}

A total of 913 consecutive patients who underwent RP at a single center between January 2016 and December 2017 were selected for analysis. Thirty-four patients who received hormone therapy before the surgery, one patient with rhabdomyosarcoma, one with no malignancies, and 115 with a PSA level $>15 \mathrm{ng} / \mathrm{mL}$ were excluded. The remaining 762 patients were included in the final analysis.

\section{Data collection}

The preoperative clinical features of patients, including age and PSA level, were reviewed from electronic medical records. From the RP specimens, the total number and volume of tumor(s), the highest GS, and the pathological stage were recorded. The GS and volume of each tumor focus were also recorded. Significant tumors were defined as those with either a tumor volume $\geq 0.5 \mathrm{~mL}$ or a GS $\geq 7(3+4)[16]$.

\section{Histopathological evaluation}

Each prostate was indicated with India ink and fixed in $10 \%$ buffered neutral formalin for $24 \mathrm{~h}$. After fixation, the apex and base were amputated and serially sectioned parallel to the urethra. Paraffin-embedded RP specimens were sectioned at $5 \mu \mathrm{m}$ thickness and stained with hematoxylin-eosin. Seminal vesicles were sectioned parallel to their junction with the prostate and submitted in entirety for evaluation. The remaining specimen was serially sectioned perpendicular to the longitudinal plane of the gland at 3- to 4-mm intervals from the apex to the base. One experienced genitourinary pathologist examined all of the specimens.

The volume of each tumor was calculated using the ellipsoid estimation described by Perera et al. $[=\mathrm{k}(\pi / 6) \times$ length $\times$ width $\times$ thickness] [17]. Length was the longest linear dimension of the largest cross-sectional profile for that focus, and width was the second longest linear dimension in the maximum cross-sectional profile, approximately at right angles to the length. Height was defined as the number of cross-sections occupied by each focus multiplied by $0.5 \mathrm{~cm}$, which was the thickness of each tissue block.

When tumor areas were separated by $>4 \mathrm{~mm}$ within the same slide or $5 \mathrm{~mm}$ in adjacent slides, the areas were regarded as separate tumor foci [18-20]. When multifocal tumors were observed, the primary tumor was defined as the largest tumor as measured by volume, without considering its GS. As secondary tumor was defined as a tumor smaller than the primary tumor. Tumor laterality was divided along the sagittal plane with the urethra as a midline. "Bilateral unifocal" denotes the presence of one tumor crossing the midline and "bilateral multifocal" refers to the presence of at least one tumor in each of the right and left lobes.

\section{Statistical analysis}

The Mann-Whitney U test was used to compare age, PSA, and prostate volume of the different groups. Pearson's chi-squared test was used to compare characteristics between the two groups based on noncontinuous variables (such as GS and pathological stage). Pearson correlation and linear regression were used to describe the relationship between total tumor volume and index tumor volume. All statistical analyses were performed using IBM SPSS version 20.0 (IBM Corp., Armonk, NY, USA). Two-sided $p$ values $<0.05$ were considered statistically significant.

\section{Results}

\section{Baseline characteristics}

Baseline characteristics of the $762 \mathrm{RP}$ specimens are presented in Table 1 . The median age of the patients was 66 years (range: $43-81$ years) and the median PSA was $5.09 \mathrm{ng} / \mathrm{mL}$ (range: $0.34-14.95 \mathrm{ng} / \mathrm{mL}$ ). The mean overall tumor volume was $3.24 \mathrm{~mL}$ (standard deviation: 4.16). The majority of the cases were multifocal 
Table 1 Baseline characteristics of 762 radical prostatectomy specimens

\begin{tabular}{|c|c|}
\hline \multicolumn{2}{|l|}{ Age, years } \\
\hline Mean \pm SD & $65.5 \pm 6.7$ \\
\hline Median (range) & $66.0(43.0-81.0)$ \\
\hline \multicolumn{2}{|l|}{$\mathrm{PSA}, \mathrm{ng} / \mathrm{mL}$} \\
\hline Mean \pm SD & $5.93 \pm 3.07$ \\
\hline Median (range) & $5.09(0.34-14.95)$ \\
\hline \multicolumn{2}{|l|}{ Tumor focality } \\
\hline Unifocal & $301(39.5 \%)$ \\
\hline Multifocal & $461(60.5 \%)$ \\
\hline \multicolumn{2}{|l|}{ Tumor laterality } \\
\hline Unilateral unifocal & $111(14.6 \%)$ \\
\hline Unilateral multifocal & $26(3.4 \%)$ \\
\hline Bilateral unifocal & 190 (24.9\%) \\
\hline Bilateral multifocal & $435(57.1 \%)$ \\
\hline \multicolumn{2}{|c|}{ Overall tumor volume, ml } \\
\hline Mean $\pm S D$ & $3.24 \pm 4.16$ \\
\hline Median (range) & $1.97(0.01-57.41)$ \\
\hline \multicolumn{2}{|l|}{ Gleason score } \\
\hline $6(3+3)$ & $86(11.3 \%)$ \\
\hline $7(3+4)$ & $434(57.0 \%)$ \\
\hline $7(4+3)$ & $140(18.4 \%)$ \\
\hline 8 & $35(4.6 \%)$ \\
\hline 9 & $67(8.8 \%)$ \\
\hline \multicolumn{2}{|l|}{ Pathologic stage } \\
\hline pT2a-b & $102(13.4 \%)$ \\
\hline pT2c & $457(60.0 \%)$ \\
\hline рT3а & $133(17.5 \%)$ \\
\hline pT3b & 69 (9.1\%) \\
\hline pT4 & $1(0.1 \%)$ \\
\hline
\end{tabular}

$P S A=$ prostate-specific antigen, $S D=$ standard deviation

(60.5\%), well-to-moderately differentiated (GS 6 and 3 $+4,68.3 \%$ ), and organ-confined (pT2, 73.4\%).

\section{Characteristics of individual tumors}

Among the 762 whole-mount specimens, 1448 tumor foci ranging in volume from 0.01 to $57.41 \mathrm{~mL}$ were identified. Table 2 shows the characteristics of the unifocal, primary, and secondary tumor foci. In multifocal disease, among the 686 secondary tumors, $250(36.4 \%)$ had a GS $\geq 7$ and $122(17.8 \%)$ had a volume $\geq 0.5 \mathrm{~mL}$. There were $166(24.2 \%)$ cases with small tumor volume $(<0.5 \mathrm{~mL})$ and Gleason pattern 4. Five secondary tumors were found to extend extra-capsularly, whereas the primary tumors were organ-confined. No secondary tumors were found to have invaded the seminal vesicles. Figure 1 shows the distribution of the number of tumors per prostate. A total of $583(76.5 \%)$ patients had one or two tumors within the prostate gland.

Of the 435 cases of bilateral multifocal disease, the secondary tumors on the contralateral lobes were significant by volume $(\geq 0.5 \mathrm{~mL})$ in $91(20.9 \%)$ cases and by grade (GS $\geq 7)$ in $179(41.1 \%)$ cases. There were $285(65.5 \%)$ specimens with at least two tumor foci within the prostate gland with a different GS, and $29(6.7 \%)$ specimens in which the secondary tumors on the contralateral lobe had a GS higher than the primary tumor score (Table 3). There were 102 $(23.4 \%)$ tumors with a small tumor volume $(<0.5 \mathrm{~mL})$ and Gleason pattern 4 on the lobe contralateral to the primary tumor.

\section{Comparison between unifocal and multifocal tumors}

Table 4 compares patient and tumor characteristics in the unifocal and multifocal disease groups. Patients with unifocal tumors had significantly higher PSA levels $(p=0.023)$, larger tumor volumes $(p<0.001)$, and higher pathologic stages $(p<0.001)$ than those with multifocal tumors.

\section{Application of hemiablation in bilateral multifocal tumors Of the 435 patients with bilateral multifocal tumors, 273 had organ-confined and GS $\leq 7(3+4)$ cancer. If focal therapy (hemiablation) is performed with the aim of ablating the lobe where the tumor with the highest GS and largest volume is located, untreated lobes may continue to harbor small, clinically signifi- cant tumor (presence of Gleason pattern 4 and a volume $<0.5 \mathrm{~mL}), 22.3 \%(61 / 273)$ of which may not be detected by prostate biopsies and MRI findings before hemiablation.}

\section{Discussion}

Focal therapy provides an opportunity for effective treatment of prostate cancer with minimal morbidity by treating only the area of cancer or the index lesions of multifocal tumors while surveillance of the remaining clinically insignificant tumors is carried out. Although focal therapy is mainly performed in low-risk cases with small tumors that enable active surveillance, in the case of intermediate-risk cancers requiring active treatment, focal therapy has the advantage of providing comparable oncologic outcomes and low toxicity compared with treatment of the whole gland.

To the best of our knowledge, the present study is the first to address the issue of tumor focality, laterality, volume, and GS in a Korean setting for the purpose of considering focal therapy (hemiablation). In other studies, secondary tumors are characterized by small volumes and well-differentiated diseases. Bott et al. [21] reported tumor characteristics at RP for 77 men at low to 
Table 2 Histological characteristics of individual tumor foci from 762 radical prostatectomy specimens

\begin{tabular}{|c|c|c|c|c|c|c|c|c|c|c|c|}
\hline \multirow[t]{2}{*}{ Tumor type } & \multirow[t]{2}{*}{ Total } & \multicolumn{2}{|l|}{$G S \geq 7$} & \multicolumn{2}{|c|}{$\mathrm{GS} \leq 6$} & \multicolumn{2}{|c|}{ Volume $\geq 0.5 \mathrm{~mL}$} & \multicolumn{2}{|l|}{ ECE } & \multicolumn{2}{|l|}{ SVI } \\
\hline & & $N$ & $\%$ & $N$ & $\%$ & $N$ & $\%$ & $N$ & $\%$ & $N$ & $\%$ \\
\hline Unifocal & 301 & 269 & 89.4 & 32 & 10.6 & 254 & 84.4 & 59 & 19.6 & 46 & 15.2 \\
\hline \multicolumn{12}{|c|}{ Multifocal } \\
\hline Primary tumors & 461 & 384 & 83.3 & 77 & 16.7 & 371 & 80.5 & 69 & 14.9 & 23 & 4.9 \\
\hline Secondary tumors & 686 & $250(166)^{a}$ & $36.4(24.2)^{a}$ & 436 & 63.6 & 122 & 17.8 & 5 & 0.7 & 0 & 0 \\
\hline Total & 1448 & 903 & & 545 & & 747 & & 133 & & 69 & \\
\hline
\end{tabular}

$E C E=$ extracapsular extension, $G S=$ Gleason score, $S V I=$ seminal vesicle invasion

${ }^{a}$ Tumor with $\mathrm{GS} \geq 7$ and volume $<0.5 \mathrm{~mL}$

The primary tumor was defined as the largest tumor as measured by volume, without considering its Gleason score. Secondary tumors were defined as all tumors that were smaller than the primary tumor

intermediate risk for prostate cancer. A total of $11.7 \%$ (9/77) had unilateral cancer and 41/77 had multifocal cancer, with 33 of the multifocal patients having an index lesion in one lobe and clinically insignificant secondary tumors in the contralateral lobe. Among eight with clinically significant secondary tumors, six were clinically significant by GS (four contralateral, two ipsilateral) and two were significant by volume (one contralateral, one ipsilateral). Karavitakis et al. [22] reported a histopathological analysis of index and non-index lesions from 100 consecutive RP specimens. Among the 170 secondary lesions, 1 (0.6\%) had a GS $\geq 7$ and $22(12.9 \%)$ were $\geq 0.5 \mathrm{~mL}$. In both studies, no patient in had a secondary tumor with had a GS higher than the score of the index tumor of the specimen. However, our data showed several clinically significant secondary tumors $(17.8 \%$ with tumor volume $\geq 0.5 \mathrm{~mL}$ and $36.4 \%$ with GS $\geq 7$ ). The greatest difference compared with previous studies is that 29 (6.6\%) of our cases had a secondary tumor with a GS higher than that of the primary tumor. Also, only three patients had a low-risk primary tumor (GS $\leq 6$ and tumor volume $<0.5 \mathrm{~mL}$ ) and secondary tumors with Gleason pattern 4 . The present study highlighted that in Korean men with prostate cancer, secondary tumors frequently have a higher GS than reported by other studies.

Although the lack of prostate biopsy and mpMRI data in this study limits evaluation of patient selection for focal therapy, our study provides additional and important information on tumors in the lobe contralateral to the primary tumor. Among 14 cases of unilateral disease examined in a previous analysis of 100 whole-mount RP specimens [22], 10 patients were suitable for hemiablation; organ-confined, and GS $\leq 7$ tumor. Among the 86 patients with bilateral disease, 35 with the index lesion confined to one lobe had secondary lesions in the contralateral lobe, with a tumor volume $<0.5 \mathrm{~mL}$ and GS $\leq 6$. There were 45 patients in this series who could be considered suitable for hemiablation. However, in our study, if hemiablation can be delivered with the aim of ablating the lobe where the highest GS and larger tumor is located, and untreated

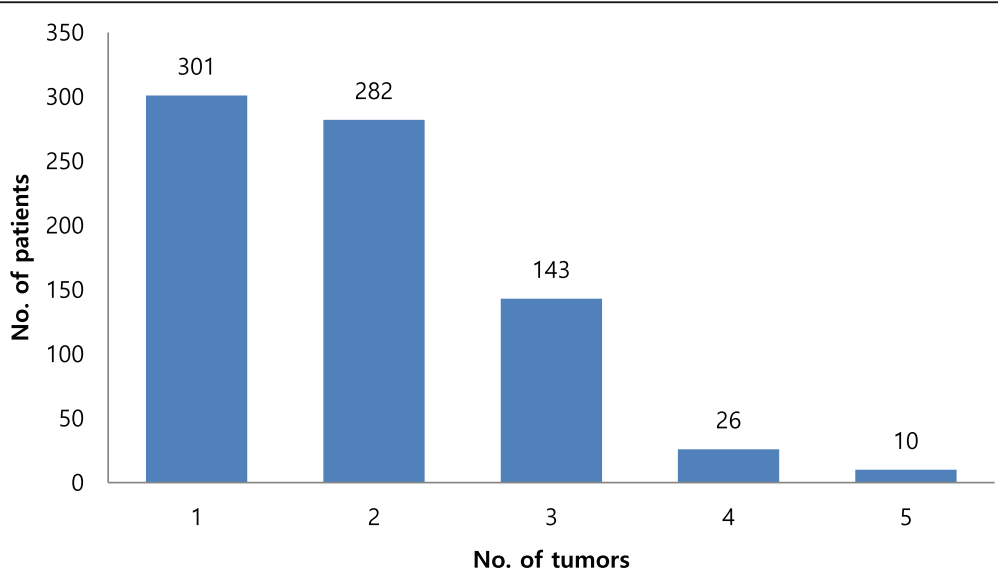

Fig. 1 Distribution of 762 patients according to the number of tumors within the prostate gland 
Table 3 Cross-tabulation of histology (Gleason score) of primary and secondary tumors on the contralateral lobe to the primary tumor among patients with bilateral multifocal tumors $(n=435)$

\begin{tabular}{|c|c|c|c|c|c|}
\hline \multirow[t]{2}{*}{ Primary tumor } & \multicolumn{4}{|c|}{ Secondary tumor on the lobe contralateral to the primary tumor, $n(\%)$} & \multirow[b]{2}{*}{ Total } \\
\hline & GS $3+3$ & GS $3+4$ & GS $4+3$ & $\mathrm{GS} \geq 8$ & \\
\hline GS $3+3$ & $48(11)$ & $15(3.4)$ & $1(0.2)$ & $1(0.2)$ & 65 \\
\hline GS $3+4$ & $149(34.2)$ & $92(21.1)$ & $8(1.8)$ & $3(0.7)$ & 252 \\
\hline GS $4+3$ & $42(9.6)$ & $26(6.0)$ & $4(0.9)$ & $1(0.2)$ & 73 \\
\hline $\mathrm{GS} \geq 8$ & $21(4.8)$ & $14(3.2)$ & $7(1.6)$ & $3(0.7)$ & 45 \\
\hline Total & 256 & 150 & 21 & 8 & 435 \\
\hline
\end{tabular}

GS $=$ Gleason score

lobes harboring clinically insignificant tumor undergo surveillance, $28 \%$ might have been appropriate for such a strategy. A possible explanation is that many clinically significant secondary tumors remain in the contralateral lobe. Because the proportion of unilateral disease is similar to that of Karavitakis [22] (11.5\% vs. $10 \%)$.

Our study data found $41.1 \%$ of cases with a GS $\geq 7$ and $20.9 \%$ with tumor volume $\geq 0.5 \mathrm{~mL}$ on the lobe contralateral to the primary tumor. More importantly, $23.4 \%$ of the cases involved small tumor volume $(<0.5 \mathrm{~mL})$ and Gleason pattern 4 on the contralateral lobe, likely because mPMRI is less diagnostic for small lesions $<0.5$ $\mathrm{mL}$. Because Korean men have more significant small, secondary tumors in the contralateral lobe, accurate prostate biopsies are particularly important to establish focal therapy strategies. Sextant random biopsies are insufficient for accurate determination of tumor location within a prostate. Instead, perineal template-guided saturation biopsy has recently been preferred to aid with

Table 4 Comparison between unifocal and multifocal tumors $(n=762)$

\begin{tabular}{lllr}
\hline & Unifocal & Multifocal & $P$ value \\
\hline $\mathrm{N}$ & 301 & 461 & \\
Age, years & & & \\
$\quad$ Mean (SD) & $64.96(7.07)$ & $65.96(6.50)$ & 0.050 \\
$\quad$ Median (range) & $65(43-80)$ & $67(45-81)$ & \\
PSA, ng/mL & & & \\
Mean (SD) & $6.25(3.25)$ & $5.72(2.94)$ & 0.023 \\
Median (range) & $5.41(0.37-14.78)$ & $4.89(0.34-14.95)$ & \\
Tumor volume, mL & & & $<0.001$ \\
Mean (SD) & $4.12(5.47)$ & $2.67(2.88)$ & \\
Median (range) & $2.34(0.01-57.41)$ & $1.72(0.01-23.13)$ & \\
Gleason Score $\geq 7$ & $269(89.4 \%)$ & $407(88.3 \%)$ & 0.644 \\
$\quad$ Stage $\geq$ T3a & $106(35.2 \%)$ & $97(21.0 \%)$ & $<0.001$ \\
\hline SD $=$ standard deviation & & &
\end{tabular}

$S D=$ standard deviation patient selection [23-25], and mpMRI has been used to select patients for clinical trials [26-28].

This study has several limitations. First, it was conducted retrospectively at a single institution, raising the possibility of selection bias. Second, it focused on histopathological analysis of RP specimens and did not include preoperative data (e.g., clinical staging and biopsy findings). Although we considered only patients with a PSA $<15 \mathrm{ng} / \mathrm{mL}$ in an effort to exclude cases of advanced prostate cancer, some patients who were not considered suitable candidates for focal therapy even before RP could have been included in the patient population. Future research should analyze RP specimens by applying additional patient selection criteria such as a preoperative PSA level $<15 \mathrm{ng} / \mathrm{mL}$, clinical stage $<\mathrm{T} 2 \mathrm{c}, \mathrm{GS} \leq 3+4$, and a Prostate Imaging Reporting and Data System score $<4$ on the contralateral lobe based on mpMRI. Our study has the additional limitation that clinical outcomes were not included in the study protocol, therefore no definitive conclusions can be made regarding the effects of tumor focality and laterality on disease progression. However, a group from Duke University demonstrated that prostate cancer laterality does not affect disease progression [29].

\section{Conclusions}

Bilateral and multifocal tumors are common features on RP specimens. Total tumor volume, GS, extracapsular extension, and seminal vesicle invasion are almost always determined by the index tumor. However, secondary tumors in Korean men frequently present with clinically significant prostate cancer. Furthermore, we observed many cases in which secondary tumors on the lobe contralateral to the primary tumor had a higher GS and small tumor volume. Additional studies are required to evaluate the accuracy of combined mpMRI and transperineal template-guided saturation biopsies in patient selection for application of hemi-ablative focal therapy. 


\section{Abbreviations}

GS: Gleason score; PSA: Prostate-specific antigen; RP: Radical prostatectomy

\section{Acknowledgments}

Not applicable.

\section{Funding}

No funding has been gained by the authors for this study.

\section{Availability of data and materials}

The datasets used and analyzed during the current study are available from the corresponding author on reasonable request.

\section{Authors' contributions}

YHC performed data analysis and wrote the manuscript. JWY helped data analysis. BCJ, SIS, SSJ, and HML carried out all surgical procedures and participated in data collection. HGJ helped to draft the manuscript and was a supervisor of this study. All authors read and approved the final manuscript.

\section{Ethics approval and consent to participate}

Our Institutional Review Board (IRB) approved this retrospective study and waived the requirement for informed consent (IRB no. 2018-04-082).

\section{Consent for publication}

Not applicable.

\section{Competing interests}

The authors declare that they have no competing interests.

\section{Publisher's Note}

Springer Nature remains neutral with regard to jurisdictional claims in published maps and institutional affiliations.

Received: 30 July 2018 Accepted: 4 January 2019

Published online: 12 January 2019

\section{References}

1. van der Poel HG, van den Bergh RCN, Briers E, Cornford P, Govorov A Henry AM, Lam TB, Mason MD, Rouviere O, De Santis M, Willemse PM, van Poppel H, Mottet N. Focal therapy in primary localised prostate cancer: the European Association of Urology position in 2018. Eur Urol. 2018;74(1):84-91.

2. Valerio M, Ahmed HU, Emberton M, Lawrentschuk N, Lazzeri M, Montironi R, Nguyen PL, Trachtenberg J, Polascik TJ. The role of focal therapy in the management of localised prostate cancer: a systematic review. Eur Urol. 2014;66:732-51.

3. Valerio M, Cerantola Y, Eggener SE, Lepor H, Polascik TJ, Villers A, Emberton M. New and established Technology in Focal Ablation of the prostate: a systematic review. Eur Urol. 2017;71:17-34.

4. Giannarini G, Gandaglia G, Montorsi F, Briganti A. Will focal therapy remain only an attractive illusion for the primary treatment of prostate cancer? J Clin Oncol. 2014:32:1299-301.

5. Valerio M, Emberton M, Ahmed HU. Focal therapy will become a standard option for selected men with localized prostate cancer. J Clin Oncol. 2014;32:3680-1.

6. Wise AM, Stamey TA, McNeal JE, Clayton JL. Morphologic and clinical significance of multifocal prostate cancers in radical prostatectomy specimens. Urology. 2002;60:264-9.

7. Algaba F, Montironi R. Impact of prostate cancer multifocality on its biology and treatment. J Endourol. 2010;24:799-804.

8. Ahmed HU, Arya M, Freeman A, Emberton M. Do low-grade and lowvolume prostate cancers bear the hallmarks of malignancy? Lancet Oncol. 2012;13:e509-17.

9. Noguchi M, Stamey TA, McNeal JE, Nolley R. Prognostic factors for multifocal prostate cancer in radical prostatectomy specimens: lack of significance of secondary cancers. J Urol. 2003;170:459-63.

10. de Rooij M, Hamoen EH, Futterer JJ, Barentsz JO, Rovers MM. Accuracy of multiparametric MRI for prostate cancer detection: a meta-analysis. AJR Am J Roentgenol. 2014;202:343-51.

11. Futterer JJ. Multiparametric MRI in the detection of clinically significant prostate Cancer. Korean J Radiol. 2017;18:597-606.
12. Futterer JJ, Briganti A, De Visschere P, Emberton M, Giannarini G, Kirkham A, Taneja SS, Thoeny H, Villeirs G, Villers A. Can clinically significant prostate Cancer be detected with multiparametric magnetic resonance imaging? A systematic review of the literature. Eur Urol. 2015;68:1045-53.

13. Le JD, Tan N, Shkolyar E, Lu DY, Kwan L, Marks LS, Huang J, Margolis DJ, Raman SS, Reiter RE. Multifocality and prostate cancer detection by multiparametric magnetic resonance imaging: correlation with wholemount histopathology. Eur Urol. 2015;67:569-76.

14. Kang DI, Chung Jl, Ha HK, Min K, Yoon J, Kim W, Seo Wl, Kang P, Jung SJ, Kim IY. Korean prostate cancer patients have worse disease characteristics than their American counterparts. Asian Pac J Cancer Prev. 2013:14:6913-7.

15. Jeong IG, Dajani D, Verghese M, Hwang J, Cho YM, Hong JH, Kim CS, Ahn $\mathrm{H}$, Ro JY. Differences in the aggressiveness of prostate cancer among Korean, Caucasian, and African American men: a retrospective cohort study of radical prostatectomy. Urol Oncol. 2016;34:3.e9-14.

16. Epstein JI, Walsh PC, Carmichael M, Brendler CB. Pathologic and clinical findings to predict tumor extent of nonpalpable (stage T1c) prostate cancer Jama. 1994;271:368-74.

17. Perera M, Lawrentschuk N, Bolton D, Clouston D. Comparison of contemporary methods for estimating prostate tumour volume in pathological specimens. BJU Int. 2014;113(Suppl 2):29-34.

18. Ruijter ET, van de Kaa CA, Schalken JA, Debruyne FM, Ruiter DJ. Histological grade heterogeneity in multifocal prostate cancer. Biological and clinical implications. J Pathol. 1996;180:295-9.

19. Ruijter ET, Miller GJ, van de Kaa CA, van Bokhoven A, Bussemakers MJ, Debruyne FM, Ruiter DJ, Schalken JA. Molecular analysis of multifocal prostate cancer lesions. J Pathol. 1999;188:271-7.

20. Mouraviev V, Sun L, Madden JF, Mayes JM, Moul JW, Polascik TJ. Prostate cancer laterality does not predict prostate-specific antigen recurrence after radical prostatectomy. Urology. 2007;70:1141-5.

21. Bott SR, Ahmed HU, Hindley RG, Abdul-Rahman A, Freeman A, Emberton M. The index lesion and focal therapy: an analysis of the pathological characteristics of prostate cancer. BJU Int. 2010;106:1607-11.

22. Karavitakis M, Winkler M, Abel P, Livni N, Beckley I, Ahmed HU. Histological characteristics of the index lesion in whole-mount radical prostatectomy specimens: implications for focal therapy. Prostate Cancer Prostatic Dis. 2011:14:46-52.

23. Crawford ED, Wilson SS, Torkko KC, Hirano D, Stewart JS, Brammell C, Wilson RS, Kawata N, Sullivan H, Lucia MS, Werahera PN. Clinical staging of prostate cancer: a computer-simulated study of transperineal prostate biopsy. BJU Int. 2005;96:999-1004.

24. Onik G, Miessau M, Bostwick DG. Three-dimensional prostate mapping biopsy has a potentially significant impact on prostate cancer management. J Clin Oncol. 2009:27:4321-6.

25. Crawford ED, Rove KO, Barqawi AB, Maroni PD, Werahera PN, Baer CA, Koul HK, Rove CA, Lucia MS, La Rosa FG. Clinical-pathologic correlation between transperineal mapping biopsies of the prostate and three-dimensional reconstruction of prostatectomy specimens. Prostate. 2013;73:778-87.

26. Singh PB, Anele C, Dalton E, Barbouti O, Stevens D, Gurung P, Arya M, Jameson C, Freeman A, Emberton M, Ahmed HU. Prostate cancer tumour features on template prostate-mapping biopsies: implications for focal therapy. Eur Urol. 2014:66:12-9.

27. Ahmed HU, Dickinson L, Charman S, Weir S, McCartan N, Hindley RG, Freeman A, Kirkham AP, Sahu M, Scott R, Allen C, Van der Meulen J, Emberton M. Focal ablation targeted to the index lesion in multifocal localised prostate Cancer: a prospective development study. Eur Urol. 2015:68:927-36.

28. Tran M, Thompson J, Bohm M, Pulbrook M, Moses D, Shnier R, Brenner P, Delprado W, Haynes AM, Savdie R, Stricker PD. Combination of multiparametric MRI and transperineal template-guided mapping biopsy of the prostate to identify candidates for hemi-ablative focal therapy. BJU Int. 2016;117:48-54.

29. Mouraviev V, Mayes JM, Sun L, Madden JF, Moul JW, Polascik TJ. Prostate cancer laterality as a rationale of focal ablative therapy for the treatment of clinically localized prostate cancer. Cancer. 2007:110:906-10. 